\section{HOWARD READ}

University of Wolverhampton

\title{
The role of drawing in the regeneration of urban spaces
}

\section{Keywords}

location drawing urban regeneration social housing embodied practice phenomenology charcoal graphite powder documenting London

\section{Abstract}

The aim of my practice is to witness and record the contested regeneration process taking place at the 1 . Elephant and Castle, specifically the site of the former Heygate social housing estate. The official representa- 2. tions of urban transformation are visually packaged to show perfect visions of the future - my drawing is 3 . used as a method of critical analysis and to challenge these representations. Working in sketchbooks onsite 4. and in the studio the drawings create a timeline of the destruction and rupture taking place in the urban 5. landscape, critically engaging with the regeneration process and what it means.

My practice-led Ph.D. research is about documenting the changing nature of Elephant and Castle in 9 . southeast London. I draw on location, compiling notational sketches and observations using a soft 10 . $6 \mathrm{~b}$ pencil in an A6 sketchbook. I then use this information to create much larger studio-based 11. 
1. drawings, some of which are collages, using charcoal and graphite powder. The materials are layered 2. to incorporate elements of specific urban history. My theoretical methodology engages with Merleau3. Ponty's phenomenological notion of embodiment.

Many aspects of urban regeneration have been overlooked. My intention has been to draw these spaces and critically analyse urban regeneration through my peripatetic, embodied practice. My primary case study is the contested regeneration of Elephant and Castle and the disappearance of public land and the loss of social housing. The act and action of my drawing is a means of experiencing and embodying the post-war historical legacy of the site.

I made the decision not to engage with the official developers as it felt like an act of complicity 10. with the privatization of the land. I sought out aerial viewpoints and locations at ground level that 11. would allow me to view visually what was taking place and survey the daily changes undisturbed.

12. The panoramic view in The Lost Estate (Figure 1) depicts the cleared land of the former Heygate 13. social housing estate and shows the proximity of the City of London, and hence the reason for the

14. regeneration. The demolition of the estate and the violent reconfiguring of the landscape by mechan-

15. ical and physical human effort were dramatic and overwhelmingly sensory. The inert land had been

16. home to thousands of people and I wanted to create an image that would reflect this. The rooftop of

17. a seven-storey student hall of a residence provided the best vantage point. The sensations of the

18. excavated landscape and the changing city views facilitated my need to experiment with expressive 19. mark making.

20. Two sheets of A1 cartridge paper are joined with tape and pinned to my studio wall and I draw 21. initially using thin sticks of willow charcoal. Gesture and movement are important as I stand and 22. draw. I block out large areas very quickly working across the surface of the sheet. Using my location 23. sketches and memory the recalled image emerges through expressive gestures. I repeatedly visit the 24. site to look again and gather further visual information and to accrue detail. By drawing I am remem-

25. bering and recounting what I have seen by moving in and out of the landscape. As I complete the 26. drawing, when I feel I have reconstructed all that I have seen and felt, I use charcoal pencils, or 27. compressed charcoal to add line and detail. Deanna Petherbridge suggests charcoal has many affini-

28. ties with construction and excavation and this connects directly with many of the themes inherent

29. within globally driven regeneration, 'significantly, the French term for rubbing-out, arrachage, implies

30. snatching or uprooting' (2010:138). Moreover, charcoal leaves traces and under drawings, it records

31. its own history. In The Lost Estate I have also added the diagrammatic signage of the Heygate estate

32. using orange rectangles, cut out from paper. The colour was chosen for its vibrancy and association

33. with the high-visibility jackets worn by the builders who appeared on site. While drawing several

34. distortions took place, most notably the tilting horizon, I was not aware of this when drawing but

35. have incorporated these inaccuracies into my process. The tilting horizon seems to symbolize the

36. pull and force of the financial centre of the city, refocusing the eye on the empty land of the housing 


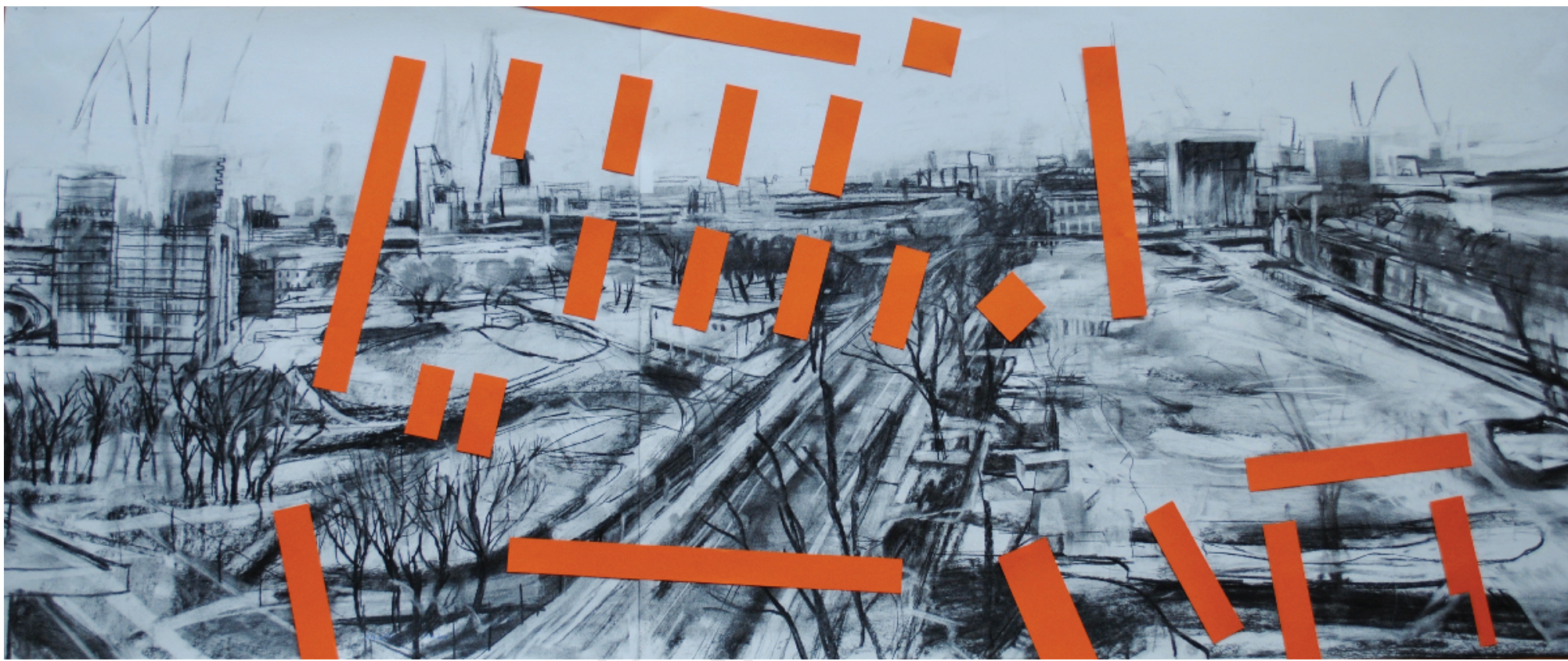

Figure 1: Howard Read, (2015-16) The lost Estate. Charcoal and collage on paper, 140 cm x 60cm. () Howard Read.
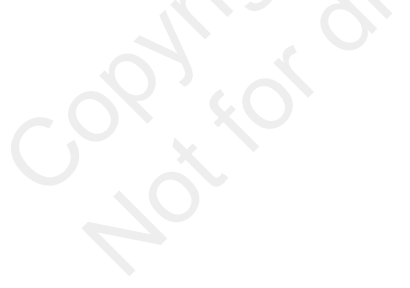


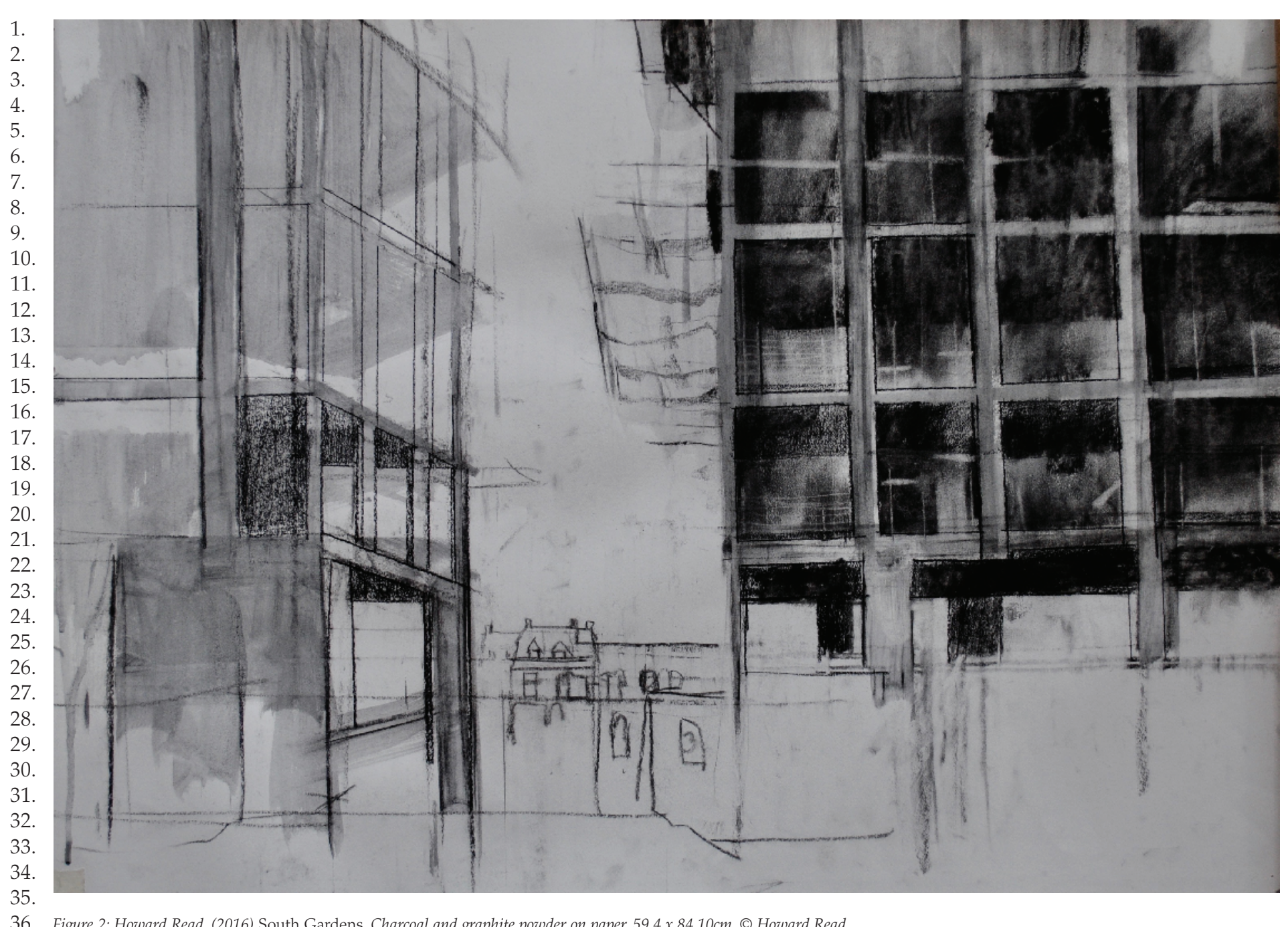


estate and its value. The combination of the charcoal drawing, overlaid with the modernist housing 1 . plan, is intended to unite past and present and show the welfare state ethos that has been lost. The 2 . mounds of rubble on the lower left hand side of the drawing are the last visible remains of the estate. 3. The final drawing does not represent a purified vision of the London imaginary but its alluvial, sedi- 4 . mented history.

South Gardens (Figure 2) is a view of one of the new development blocks, situated on the empty 6. land depicted in Figure 1. The view is from ground level looking upwards and the scale of the 7 . construction sits uneasily with the traditional Victorian terraced street behind. The drips and spill- 8 . age seeping off the lower edges of the drawing are a mixture of graphite powder and acrylic retarder, 9. thinned with water. It is the first added layer in the accretion of the drawing and the marks are at 10. odds with the vertical luxury the buildings are intended to represent. Using a brush I have applied 11. the graphite liquid to suggest the rawness of poured concrete. The solidity of the emerging struc- 12 . ture on the right-hand side, and its fortress like upper floors is juxtaposed with the linear astrin- 13. gency of the structure on the left, suggesting the inevitable erosion and dilapidation that will occur 14 . over time. It is this stage in the construction process, when a building has no architectural embel- 15. lishments, I find most revealing. The dark, interior spaces are drawn with compressed charcoal and 16. give no hint of being inhabited. The emerging structures of the buildings resemble the ruins they 17 . will become.

My studio-based drawings are the antithesis of the linear and controlled drawings of the plan- 19. ners and architects. My visual understanding of regeneration is expressive and gestural, mirroring 20. the cycle of demolition and construction. The dynamics of urban regeneration and the loss of publi- 21. cally owned land and social housing are the driving intentions behind bearing witness to the regen- 22 . eration at the Elephant and Castle and my drawing process. Reflectively itemizing each phase of my 23 . drawing procedure, which is subjective and derived from intuition, has been of critical importance to 24 . my practice-led research. My drawing actions had previously become professionally naturalized, and 25 . so unrealized. The critical probing and evaluation of my process has applied directly to my studio 26. drawings. My practice-led research has emphasized the importance of looking without drawing and 27. then looking through drawing.

\section{References}

Merleau-Ponty, M. ([1945] 2014), Phenomenology of Perception (trans. A. D. Landas), Abingdon: 32 Routledge.

Petherbridge, D. (2010), The Primacy of Drawing, London: Yale University Press. . (1) .

(1)

.

.

11.

13.

7.
8. 19.

.




\section{Suggested citation}

Read, H. (2017), 'The role of drawing in the regeneration of urban spaces', Drawing: Research, Theory, Practice, 2:2, pp. 395-400, doi: 10.1386/drtp.2.2.395_1

\section{Contributor details}

Howard Read is a Senior Lecturer at the University of Wolverhampton and a Ph.D. candidate at Manchester Metropolitan University. His research is practice led and the title of his thesis is the role of drawing in the regeneration of urban spaces.

Contact: University of Wolverhampton, School of Art, Department of Visual Communication, Room MK302, Molineux Street, Wolverhampton, WV1 1DT, UK.

E-mail: h.read@wlv.ac.uk

Howard Read has asserted his right under the Copyright, Designs and Patents Act, 1988, to be identified as the author of this work in the format that was submitted to Intellect Ltd. 